\title{
O Pró-Saúde e o PET-Saúde como ferramentas transformadoras do ensino em saúde: uma revisão integrativa
}

\author{
The Pró-Saúde and the PET-Saúde programs as transformative tools in \\ health education: an integrative review \\ El Pro-Salud y el PET - Salud como instrumentos transformación de la educación \\ en salud: una revisión integradora \\ Quitéria Lívia Muniz Mira ${ }^{1}$, Maristela Inês Osawa Vasconcelos ${ }^{2}$, Ana Suelen Pedroza Cavalcante ${ }^{3}$, \\ Eliany Nazaré Oliveira ${ }^{4}$, Roberta Cavalcante Muniz Lira ${ }^{5}$, Antonia Juliana Muniz Mira ${ }^{6}$ \\ ${ }^{1}$ Mestre em Saúde da Família pela Universidade Federal do Ceará-UFC/Campus Sobral - Universidade Federal \\ do Ceará - UFC \\ ${ }^{2}$ Doutora em Enfermagem pela Universidade Federal do Ceará - UFC) \\ ${ }^{3}$ Mestranda em Saúde da Família pela Universidade Federal do Ceará-UFC/Campus Sobral - Universidade \\ Federal do Ceará - UFC \\ ${ }^{4}$ Doutora em Enfermagem pela Universidade Federal do Ceará - UFC \\ ${ }^{5}$ Doutora em Saúde Pública pela Faculdade de Saúde Pública/Universidade de São Paulo-USP- Universidade \\ Federal do Ceará - UFC \\ ${ }^{6}$ Especialista em Enfermagem Intensivista pela UERJ e em Gestão da Qualidade em Saúde no Albert Einstein \\ Instituto Israelita de Ensino e Pesquisa - Universidade Federal do Ceará - UFC
}

\section{RESUMO}

Trata-se de uma revisão integrativa da literatura, onde foi realizado um levantamento de estudos junto às bases de dados eletrônicas da CAPES e da biblioteca digital de teses e dissertações da UFC, cujo objetivo é identificar e caracterizar as produções científicas derivadas do Pró-Saúde e do PET-Saúde no Brasil. A análise dos resultados dos 15 estudos selecionados foi realizada de forma descritiva, sendo dividida em dois subitens, com a finalidade de caracterizar as publicações, sendo eles: perfil das publicações e as categorias encontradas com maior relevância. Assim, a partir dos achados constatase que após a implementação desses programas, mudanças significativas vêm sendo induzidas na

${ }^{*}$ Quitéria Lívia Muniz Mira. E-mail: quiterialivia@hotmail.com 
perspectiva da reorientação da formação profissional em saúde. Apesar, da existência de algumas limitações e fragilidades no processo de implementação dos programas, que se constituem como desafios a serem enfrentados para o alcance efetivo de mudanças no ensino na área da saúde.

Palavras-chave: Política de Saúde. Integridade cientifica. Educação Superior. Sistema Único de Saúde.

\begin{abstract}
This is an integrative literature review, with a survey of studies in the electronic databases from CAPES and in the digital library of theses and dissertations of UFC, which aims to identify and characterize the scientific production derived from the Brazilian Programs Pró-Saúde and PETSaúde. The results analysis of the 15 studies selected were performed descriptively, being divided into two sub-items, in order to characterize the publications, namely: profile of publications, and categories found that were more relevant. Thus, the findings show that after the implementation of these programs, significant changes have been induced in view of the reorientation of professional training in health. Despite the existence of some limitations and weaknesses in the process of implementation of the programs, which are challenges to be faced to effectively accomplishchanges in education in the health field.
\end{abstract}

Keywords: Health Policy. Scientific Integrity. College education. Health Unic System.

\title{
RESUMEN
}

Se trata de una revisión integradora de la literatura, donde se realizó un levantamiento de estudios junto a las bases de datos electrónicos de la CAPES y de la biblioteca digital de tesis y disertaciones de la UFC, cuyo objetivo es identificar y caracterizar las producciones derivadas del Pro Salud y del PET Salud en Brasil. El análisis de los 15 estudios fue realizado de forma descriptible cuanto al perfil de las publicaciones y las categorías encontradas con gran relevancia. Así, a partir de los hallazgos se constata que después de la implementación de esos programas, cambios significativos han sido inducidos en la perspectiva de la reorientación de la formación profesional en salud. A pesar de la existencia de algunas limitaciones en el proceso de implementación que se constituyen como desafíos a enfrentarse para el alcance efectivo de cambios en la enseñanza en el área de la salud.

Palabras clave: Política de Salud. Integridad Científica. Educación universitaria. Sistema único de Salud.

\section{INTRODUÇÃo}

A preocupação com o processo de formação dos profissionais em saúde no Brasil não é recente. O país acompanhou o movimento global com o escopo de adequar os perfis profissionais às necessidades de saúde da população e ao fortalecimento dos Sistemas Nacionais de Saúde ${ }^{1,2}$. A discussão em torno da elaboração de propostas que pudessem se configurar como contra-hegemônicas antecede até mesmo a criação e a implantação do Sistema Único de Saúde (SUS), sendo contemporânea do movimento da medicina comunitária, que ganhou força no âmbito dos departamentos de medicina 
preventiva. O processo de formação ganha destaque nesse momento histórico, à medida que se discutia a incoerência de uma reforma do setor saúde, sem a necessária reforma do processo de formação da força de trabalho, que seria a sustentação deste ${ }^{3}$.

O processo de formação dos profissionais de saúde começa a ocupar espaço nas conferências nacionais de saúde, sendo um dos temas incluídos na proposta da Reforma Sanitária Brasileira. Deste período até a atualidade, as iniciativas, movimentos e políticas com foco na reorientação da formação em saúde assumiram configurações distintas ${ }^{4}$ buscando-se para tal propósito o estreitamento das relações entre as instituições formadoras, o sistema público de saúde e a comunidade.

Dentre as iniciativas mais recentes para esse propósito pode-se citar o Programa de Reorientação da Formação Profissional em Saúde (Pró-Saúde), criado em 2005 pelo Ministério da Saúde em parceria com o Ministério da Educação. A ideia central do programa era promover a integração ensinoserviço para a reorientação da formação profissional em uma abordagem integral e contextualizada do processo saúde-doença. Esta proposta enfatiza ainda a atenção básica e a promoção de transformações nos processos de geração de conhecimentos, relacionando as necessidades sociais às dimensões históricas, econômicas e culturais dos distintos grupos 5 .

Nesta perspectiva, tentava-se diminuir o distanciamento entre a teoria construída durante a formação acadêmica e as reais necessidades de saúde da população, por propiciar a formação de profissionais críticos e reflexivos, aptos a atuar de forma interdisciplinar, comprometidos com suas responsabilidades sociais, conhecimentos técnicos e com o aprimoramento da qualidade do ensino superior ${ }^{5,6}$.

No entanto, em 2008, durante o processo de avaliação do Pró-saúde, observou-se a necessidade de estratégias mais específicas e de financiamento de atividades que contribuíssem para a efetivação da integração ensino-serviço ${ }^{7}$.

Deste modo, em 2008, para complementar a atuação do Pró-Saúde, foi desenvolvido o Programa de Educação pelo Trabalho para a Saúde (PET-Saúde), que se caracteriza como uma estratégia para fomentar a formação de grupos de aprendizagem tutorial em áreas prioritárias para o SUS, inserindo os estudantes das graduações em saúde nos espaços dos serviços, estimulando a integração entre ensino, serviço e comunidade. Além disso, estimular a constante capacitação dos trabalhadores já inseridos no campo de trabalho, tornando-os co-produtores de conhecimentos e práticas que deem conta das diferentes demandas da população assistida pelo sistema de saúde público brasileiro ${ }^{7}$.

Compreende-se, então, que essas iniciativas representam estratégias potenciais para redirecionar a formação profissional em saúde, ressignificando o processo de aproximação entre as estruturas educacionais e as políticas de saúde vigentes. Em decorrência disso, evidencia-se a necessidade de que os programas produzam resultados efetivos quanto à contribuição para a melhoria do fazer profissional no âmbito do SUS. Logo, torna-se relevante desenvolver estudos que busquem averiguar como o processo de implementação da política nacional de reorientação profissional tem sido conduzido, na prática, dentro das instituições de ensino superior, identificando, nas suas relações institucionais e entre seus diferentes atores, evidências que apontem resultados efetivos na formação em saúde.

Este artigo objetiva identificar e caracterizar as produções científicas derivadas do Programa de Reorientação da Formação Profissional em Saúde (Pró-Saúde) e do Programa de Educação pelo Trabalho para a Saúde (PET-Saúde) no Brasil, com enfoque principal na formação acadêmica dos profissionais de saúde neles inseridos, considerando 
a relevância de tais programas na articulação ensinoserviço-comunidade.

\section{MÉTODO}

Trata-se de uma pesquisa bibliográfica, de abordagem qualitativa, exploratório-descritiva, que segue os pressupostos da revisão integrativa de literatura. A investigação iniciou a partir da seguinte pergunta de pesquisa: o que a literatura científica brasileira tem divulgado sobre a Política Nacional de Reorientação Profissional em Saúde a partir do Pró-Saúde e PETSaúde?

A revisão integrativa é uma prática que vem sendo difundida, pois "possibilita a síntese das pesquisas disponíveis, relativas a um determinado problema, com a finalidade de direcionar a prática fundamentada em conhecimento científico", possibilitando mostrar lacunas no conhecimento e explicitar as áreas que carecem de mais pesquisas.

No processo de problematização acerca do tema central, reorientação da formação profissional em saúde, foi realizado um levantamento de estudos já desenvolvidos sobre a temática junto às bases de dados eletrônicas. Utilizou-se como referência o portal de periódicos da Coordenação de Aperfeiçoamento de Pessoal de Nível Superior (CAPES) e a biblioteca digital de teses e dissertações da Universidade Federal do Ceará (UFC). Pretendeuse, ao final, conhecer o maior número possível de produções referentes à reorientação profissional em saúde, em âmbito nacional, regional e local, este representado pela Universidade Estadual Vale do Acaraú - UVA e Universidade Federal do Ceará UFC/Campus Sobral.

Em consulta realizada em maio de 2015, empreendeuse uma busca avançada por assunto no portal de periódicos da CAPES utilizando as palavras-chave formação em saúde e política pública, sendo selecionados os artigos publicados nos últimos 10 anos. Aplicados os critérios de busca, foram listados 1.242 artigos e quando selecionado o idioma português, 552. Na biblioteca digital de teses e dissertações da UFC, ao realizar a busca avançada por palavras-chave, nenhum resultado foi encontrado. Alterando a busca por programas de Pós-Graduação, selecionados os programas de Saúde da Família e Saúde Pública, identificou-se uma dissertação no Mestrado em Saúde da Família, Campus Sobral.

Após a identificação dos estudos, procedeu-se a leitura minuciosa de seus resumos, para obter maiores informações sobre o que versavam e como contribuíam para ampliar conhecimentos sobre o tema. Nesta etapa, elegeu-se como critério de inclusão constar os termos Pró-Saúde e/ou PET-Saúde, uma vez que estes são estratégias desenvolvidas com o intuito de reorientar a formação profissional. Em seguida, excluídas as indexações concomitantes, foram lidos os títulos e resumos das produções, aplicando-se os critérios de inclusão para compor a amostra a ser submetida a uma análise detalhada: artigos em português, disponíveis na íntegra e publicados após o ano de 2005, já que este foi o ano de criação do Pró-Saúde.

Foram excluídos os textos editoriais, relatórios, cartas, resenhas, trabalhos de conclusão de curso e artigos duplicados. Este processo de leitura foi realizado de maio a julho de 2015, sendo selecionados 13 artigos no Portal de Periódicos CAPES e uma dissertação no Banco de Teses e Dissertações da UFC, sendo esta selecionada por meio da busca em Programas de Pós-Graduação (Saúde da Família e Saúde Coletiva).

Para análise dos estudos foi realizada a leitura minuciosa dos trabalhos na íntegra. Para seguir as diretrizes da Revisão Integrativa, a partir da revisão dos achados estruturada nos campos de organização dos dados, a análise ocorreu a partir da inter-relação de itens. Dentro de cada item as ideias foram agrupadas por similaridade, de modo a se desenvolver uma síntese de forma narrativa. 


\section{RESULTADOS}

Optou-se por apresentar uma síntese deste levantamento (Quadro 1), na qual foram extraídas informações consideradas relevantes a partir das produções selecionadas, tais como: perfil dos autores, título, periódico, ano de publicação, tipo de programa (PET-Saúde, e/ou Pró-Saúde), cenário do estudo, objetivos, método empregado e principais achados.

Quadro 1 - Estudos incluídos na busca sobre Pró-Saúde e PET-Saúde em maio de 2015

\begin{tabular}{|c|c|c|c|c|c|c|c|}
\hline AUTOR & TÍTULO & REVISTA & $\stackrel{0}{Z}$ & $\begin{array}{l}\text { PRO- } \\
\text { GRAMA }\end{array}$ & CENÁRIO & OBJETIVO & MÉTODO \\
\hline $\begin{array}{c}\text { Dias, } \\
\text { Lima, } \\
\text { Teixeira }\end{array}$ & $\begin{array}{l}\text { A trajetória da } \\
\text { política nacional } \\
\text { de reorientação } \\
\text { da formação } \\
\text { profissional em } \\
\text { saúde no SUS. }\end{array}$ & $\begin{array}{l}\text { Ciência } \\
\text { e Saúde } \\
\text { Coletiva }\end{array}$ & $\stackrel{\text { m}}{\stackrel{\text { }}{~}}$ & $\begin{array}{l}\text { Pró- } \\
\text { Saúde; } \\
\text { PET- } \\
\text { Saúde; }\end{array}$ & & $\begin{array}{l}\text { Analisar a } \\
\text { política nacional } \\
\text { de reorientação } \\
\text { da formação } \\
\text { profissional em } \\
\text { saúde, desenvolvida a } \\
\text { partir de } 2003 \text {, e seus } \\
\text { antecedentes. }\end{array}$ & $\begin{array}{l}\text { Revisão de literatura } \\
\text { sobre o tema e } \\
\text { análise documental } \\
\text { apoiados no } \\
\text { referencial teórico } \\
\text { de análise das } \\
\text { políticas públicas, } \\
\text { em especial o } \\
\text { institucionalismo } \\
\text { histórico. }\end{array}$ \\
\hline $\begin{array}{c}\text { Morais, } \\
\text { et al }\end{array}$ & $\begin{array}{l}\text { A reorientação } \\
\text { do ensino e } \\
\text { da prática em } \\
\text { enfermagem: } \\
\text { implantação do } \\
\text { Pró-Saúde em } \\
\text { Mossoró, Brasil. }\end{array}$ & $\begin{array}{l}\text { Revista } \\
\text { Gaucha de } \\
\text { Enfermagem }\end{array}$ & 웅 & $\begin{array}{l}\text { Pró- } \\
\text { Saúde }\end{array}$ & $\begin{array}{l}\text { Faculdade de } \\
\text { Enfermagem } \\
\text { (FAEN) da } \\
\text { Universidade } \\
\text { do Estado do } \\
\text { Rio Grande do } \\
\text { Norte (UERN) e } \\
\text { UBS. }\end{array}$ & $\begin{array}{l}\text { Conhecer a } \\
\text { implantação e } \\
\text { inserção do Pró-Saúde } \\
\text { em Mossoró-RN, } \\
\text { para entender como } \\
\text { os atores da atenção } \\
\text { básica se posicionam } \\
\text { diante da articulação } \\
\text { ensino/serviço. }\end{array}$ & $\begin{array}{l}\text { Estudo descritivo } \\
\text { com abordagem } \\
\text { qualitativa. }\end{array}$ \\
\hline $\begin{array}{c}\text { Kleba, } \\
\text { et al }\end{array}$ & $\begin{array}{l}\text { Práticas de } \\
\text { reorientação na } \\
\text { formação em } \\
\text { saúde: relato de } \\
\text { experiência da } \\
\text { universidade } \\
\text { comunitária } \\
\text { da região de } \\
\text { Chapecó. }\end{array}$ & $\begin{array}{l}\text { Ciência, } \\
\text { Cuidado e } \\
\text { Saúde }\end{array}$ & $\stackrel{\sim}{\overparen{乛}}$ & $\begin{array}{l}\text { Pró- } \\
\text { Saúde }\end{array}$ & $\begin{array}{l}\text { Universidade } \\
\text { Comunitária } \\
\text { da Região } \\
\text { de Chapecó } \\
\text { (Unochapecó). }\end{array}$ & $\begin{array}{l}\text { Relatar projetos } \\
\text { do Pró-Saúde } \\
\text { implementados em } \\
\text { Chapecó, de modo a } \\
\text { integrar - por meio de } \\
\text { ações pedagógicas - o } \\
\text { processo de formação } \\
\text { acadêmica aos } \\
\text { serviços de saúde. }\end{array}$ & $\begin{array}{l}\text { Relato de } \\
\text { experiência } \\
\text { com abordagem } \\
\text { qualitativa. }\end{array}$ \\
\hline $\begin{array}{l}\text { Brito; } \\
\text { Coelho }\end{array}$ & $\begin{array}{l}\text { Formação do } \\
\text { Enfermeiro } \\
\text { para a atenção } \\
\text { básica: análise } \\
\text { da orientação } \\
\text { teórica, cenários } \\
\text { de pratica e } \\
\text { orientação } \\
\text { pedagógica a } \\
\text { partir de um curso } \\
\text { de graduação. }\end{array}$ & $\begin{array}{l}\text { Banco de } \\
\text { teses e } \\
\text { dissertações } \\
\text { da } \\
\text { Universidade } \\
\text { Federal do } \\
\text { Ceará (UFC) }\end{array}$ & 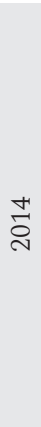 & $\begin{array}{l}\text { Pró- } \\
\text { Saúde }\end{array}$ & $\begin{array}{l}\text { Curso de } \\
\text { Enfermagem da } \\
\text { Universidade } \\
\text { Estadual Vale } \\
\text { do Acaraú } \\
\text { (UVA). }\end{array}$ & $\begin{array}{l}\text { Analisar a atuação } \\
\text { do Enfermeiro para } \\
\text { a Atenção Básica, no } \\
\text { curso de Enfermagem } \\
\text { da UVA, segundo os } \\
\text { eixos norteadores do } \\
\text { Pró-Saúde. }\end{array}$ & $\begin{array}{l}\text { Estudo exploratório- } \\
\text { descritivo com } \\
\text { abordagem quanti- } \\
\text { qualitativa. }\end{array}$ \\
\hline
\end{tabular}




\begin{tabular}{|c|c|c|c|c|c|c|c|}
\hline AUTOR & TÍTULO & REVISTA & $\stackrel{0}{Z}$ & $\begin{array}{l}\text { PRO- } \\
\text { GRAMA }\end{array}$ & CENÁRIO & OBJETIVO & MÉTODO \\
\hline $\begin{array}{l}\text { Leite, } \\
\text { et al }\end{array}$ & $\begin{array}{l}\text { O Programa } \\
\text { de Educação } \\
\text { pelo Trabalho } \\
\text { para a Saúde } \\
\text { na formação } \\
\text { profissional }\end{array}$ & $\begin{array}{l}\text { Revista } \\
\text { Brasileira } \\
\text { de } \\
\text { Educação } \\
\text { Médica }\end{array}$ & $\stackrel{\circ}{\circ}$ & $\begin{array}{l}\text { PET- } \\
\text { Saúde }\end{array}$ & $\begin{array}{l}\text { Universidade } \\
\text { Estadual } \\
\text { de Montes } \\
\text { Claros } \\
\text { (Unimontes) } \\
\text { e ESF }\end{array}$ & $\begin{array}{l}\text { Descrever as experiências de } \\
\text { implantação do PET-Saúde } \\
\text { na Unimontes e ESF de } \\
\text { Montes Claros pelas equipes } \\
\text { de trabalho no período de } \\
2009 \text { a } 2010 \text { e refletir sobre os } \\
\text { aspectos potencializadores e } \\
\text { dificultadores, tendo em vista a } \\
\text { formação profissional. }\end{array}$ & $\begin{array}{l}\text { Relato de } \\
\text { experiência } \\
\text { retrospectivo e } \\
\text { descritivo com } \\
\text { abordagem } \\
\text { qualitativa. }\end{array}$ \\
\hline $\begin{array}{l}\text { Neumann } \\
\text { e Miranda }\end{array}$ & $\begin{array}{l}\text { Ensino de } \\
\text { Atenção Primária } \\
\text { à Saúde na } \\
\text { Graduação: } \\
\text { Fatores que } \\
\text { influenciam a } \\
\text { satisfação do } \\
\text { aluno }\end{array}$ & $\begin{array}{l}\text { Revista } \\
\text { Brasileira } \\
\text { de } \\
\text { Educação } \\
\text { Médica }\end{array}$ & $\stackrel{\circ}{\circ}$ & $\begin{array}{l}\text { PET- } \\
\text { Saúde }\end{array}$ & $\begin{array}{l}\text { Universidade } \\
\text { Federal do } \\
\text { Rio Grande } \\
\text { do Sul } \\
\text { (UFRS) }\end{array}$ & $\begin{array}{l}\text { Avaliar se as mudanças } \\
\text { implementadas no currículo } \\
\text { da Medicina relacionadas } \\
\text { à disciplina Métodos de } \\
\text { Abordagem em Saúde } \\
\text { Comunitária - mudança de } \\
\text { semestre e inclusão no projeto } \\
\text { PET-Saúde - produziram } \\
\text { diferenças na percepção dos } \\
\text { alunos sobre a disciplina. }\end{array}$ & $\begin{array}{l}\text { Estudo de } \\
\text { abordagem } \\
\text { quanti- } \\
\text { qualitativa. }\end{array}$ \\
\hline $\begin{array}{c}\text { Tanaka, } \\
\text { et al }\end{array}$ & $\begin{array}{l}\text { Projeto } \\
\text { PET-Saúde: } \\
\text { Ferramenta de } \\
\text { Aprendizado } \\
\text { na Formação } \\
\text { Profissional em } \\
\text { Saúde }\end{array}$ & $\begin{array}{l}\text { Revista } \\
\text { Brasileira } \\
\text { de } \\
\text { Educação } \\
\text { Médica }\end{array}$ & $\stackrel{\circ}{\circ}$ & $\begin{array}{l}\text { PET- } \\
\text { Saúde }\end{array}$ & $\begin{array}{l}\text { Universidade } \\
\text { Estadual de } \\
\text { Londrina } \\
\text { (UEL) e } \\
\text { UBSs locais. }\end{array}$ & $\begin{array}{l}\text { Relatar a experiência de um } \\
\text { grupo PET-Saúde na utilização } \\
\text { do projeto como ferramenta } \\
\text { para ensinar/ aprender a } \\
\text { importância do uso de dados } \\
\text { epidemiológicos para avaliação } \\
\text { das políticas e ações de saúde. }\end{array}$ & $\begin{array}{l}\text { Relato de } \\
\text { experiência } \\
\text { de abordagem } \\
\text { qualitativa. }\end{array}$ \\
\hline $\begin{array}{c}\text { Morais, } \\
\text { et al }\end{array}$ & $\begin{array}{l}\text { A importância } \\
\text { do PET-Saúde } \\
\text { para a formação } \\
\text { acadêmica do } \\
\text { enfermeiro. }\end{array}$ & $\begin{array}{l}\text { Trabalho, } \\
\text { Educação } \\
\text { e Saúde }\end{array}$ & 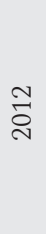 & $\begin{array}{l}\text { PET- } \\
\text { Saúde }\end{array}$ & $\begin{array}{l}\text { Universidade } \\
\text { do Estado do } \\
\text { Rio Grande } \\
\text { do Norte } \\
\text { (UERN) }\end{array}$ & $\begin{array}{l}\text { Relatar as ações desenvolvidas } \\
\text { pelo PET-Saúde da UERN, } \\
\text { enfocando a importância da } \\
\text { participação nesse projeto } \\
\text { para a formação em saúde/ } \\
\text { enfermagem }\end{array}$ & $\begin{array}{l}\text { Relato de } \\
\text { experiência } \\
\text { com } \\
\text { abordagem } \\
\text { qualitativa. }\end{array}$ \\
\hline $\begin{array}{c}\text { Caldas, } \\
\text { et al }\end{array}$ & $\begin{array}{l}\text { A percepção de } \\
\text { alunos quanto } \\
\text { ao Programa de } \\
\text { Educação Pelo } \\
\text { Trabalho para } \\
\text { a Saúde - PET- } \\
\text { Saúde. }\end{array}$ & $\begin{array}{l}\text { Revista } \\
\text { Brasileira } \\
\text { de } \\
\text { Educação } \\
\text { Médica }\end{array}$ & 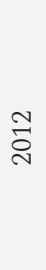 & $\begin{array}{l}\text { PET- } \\
\text { Saúde }\end{array}$ & $\begin{array}{l}\text { Universidade } \\
\text { Federal de } \\
\text { Minas Gerais } \\
\text { (UFMG) }\end{array}$ & $\begin{array}{l}\text { Investigar a percepção de } \\
\text { alunos quanto ao método de } \\
\text { integração interdisciplinar } \\
\text { entre ensino, pesquisa e } \\
\text { extensão proposto pelo PET- } \\
\text { Saúde. }\end{array}$ & $\begin{array}{l}\text { Estudo } \\
\text { seccional com } \\
\text { abordagem } \\
\text { quantitativa. }\end{array}$ \\
\hline $\begin{array}{c}\text { Rodrigues, } \\
\text { Sousa e } \\
\text { Pereira }\end{array}$ & $\begin{array}{l}\text { Rede PET-Saúde } \\
\text { em Feira de } \\
\text { Santana: o desafio } \\
\text { da integralidade. }\end{array}$ & $\begin{array}{l}\text { Revista } \\
\text { Baiana } \\
\text { de Saúde } \\
\text { Pública }\end{array}$ & 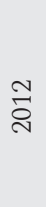 & $\begin{array}{l}\text { PET- } \\
\text { Saúde }\end{array}$ & $\begin{array}{l}\text { Universidade } \\
\text { Estadual } \\
\text { de Feira } \\
\text { de Santana } \\
\text { (UEFS) }\end{array}$ & $\begin{array}{l}\text { Discutir as possibilidades da } \\
\text { consolidação da Integralidade } \\
\text { na formação dos profissionais } \\
\text { e nas mudanças na Rede de } \\
\text { Atenção à Saúde. }\end{array}$ & $\begin{array}{l}\text { Relato de } \\
\text { experiência } \\
\text { com } \\
\text { abordagem } \\
\text { qualitativa. }\end{array}$ \\
\hline
\end{tabular}


O Pró-Saúde e o PET-Saúde como ferramentas transformadoras do ensino em saúde: uma revisão integrativa

\begin{tabular}{|c|c|c|c|c|c|c|c|}
\hline AUTOR & TÍTULO & REVISTA & $\stackrel{0}{Z}$ & $\begin{array}{l}\text { PRO- } \\
\text { GRAMA }\end{array}$ & CENÁRIO & OBJETIVO & MÉTODO \\
\hline $\begin{array}{l}\text { Pereira, } \\
\text { et al }\end{array}$ & $\begin{array}{l}\text { Contribuições da } \\
\text { educação tutorial } \\
\text { e reorientação da } \\
\text { formação para } \\
\text { enfermagem: uma } \\
\text { salada saudável! }\end{array}$ & $\begin{array}{l}\text { Revista de } \\
\text { Enfermagem } \\
\text { da UFSM }\end{array}$ & $\stackrel{m}{\circ}$ & $\begin{array}{l}\text { PET- } \\
\text { Saúde }\end{array}$ & $\begin{array}{l}\text { Faculdade de } \\
\text { Enfermagem da } \\
\text { Universidade } \\
\text { Federal de } \\
\text { Pelotas (FEn/ } \\
\text { UFPel). }\end{array}$ & $\begin{array}{l}\text { Apresentar a experiência } \\
\text { do Programa de } \\
\text { Educação pelo Trabalho } \\
\text { para a Saúde e seus } \\
\text { reflexos na formação } \\
\text { do acadêmico de } \\
\text { Enfermagem. }\end{array}$ & $\begin{array}{l}\text { Relato de } \\
\text { experiência } \\
\text { com } \\
\text { abordagem } \\
\text { qualitativa. }\end{array}$ \\
\hline 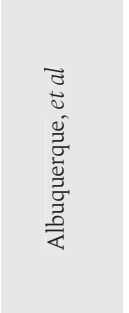 & $\begin{array}{l}\text { Educação pelo } \\
\text { trabalho para } \\
\text { a formação do } \\
\text { médico. }\end{array}$ & $\begin{array}{l}\text { Trabalho, } \\
\text { Educação e } \\
\text { Saúde }\end{array}$ & $\stackrel{m}{\stackrel{n}{\sim}}$ & $\begin{array}{l}\text { PET- } \\
\text { Saúde }\end{array}$ & $\begin{array}{l}\text { Cursos de } \\
\text { Medicina } \\
\text { de duas } \\
\text { Universidades } \\
\text { de Curitiba. }\end{array}$ & $\begin{array}{l}\text { Avaliar as } \\
\text { potencialidades e } \\
\text { limitações de três } \\
\text { experiências do PET- } \\
\text { Saúde para a formação } \\
\text { médica. }\end{array}$ & $\begin{array}{l}\text { Optou- } \\
\text { se pelo } \\
\text { método do } \\
\text { materialismo } \\
\text { histórico- } \\
\text { dialético, } \\
\text { abordagem } \\
\text { qualitativa. }\end{array}$ \\
\hline $\begin{array}{l}\text { Santos, } \\
\text { et al }\end{array}$ & $\begin{array}{l}\text { Percepção } \\
\text { discente sobre } \\
\text { a influência de } \\
\text { estágio extramuro } \\
\text { na formação } \\
\text { acadêmica } \\
\text { odontológica. }\end{array}$ & $\begin{array}{l}\text { Revista de } \\
\text { Odontologia } \\
\text { da UNESP }\end{array}$ & $\stackrel{m}{\stackrel{n}{\sim}}$ & $\begin{array}{l}\text { PET- } \\
\text { Saúde }\end{array}$ & $\begin{array}{l}\text { Universidade } \\
\text { Federal do } \\
\text { Espírito Santo } \\
\text { (UFES) }\end{array}$ & $\begin{array}{l}\text { Verificar, sob a ótica } \\
\text { dos acadêmicos de } \\
\text { Odontologia da UFES, } \\
\text { a influência que as } \\
\text { atividades extramuros do } \\
\text { Pet-Saúde exercem em } \\
\text { sua formação acadêmica. }\end{array}$ & $\begin{array}{l}\text { Estudo } \\
\text { exploratório } \\
\text { descritivo, } \\
\text { com } \\
\text { abordagem } \\
\text { quanti- } \\
\text { qualitativa. }\end{array}$ \\
\hline $\begin{array}{l}\text { Pinto, } \\
\text { et al }\end{array}$ & $\begin{array}{l}\text { Percepção dos } \\
\text { alunos de uma } \\
\text { universidade } \\
\text { pública sobre } \\
\text { o Programa de } \\
\text { Educação pelo } \\
\text { Trabalho para a } \\
\text { Saúde. }\end{array}$ & $\begin{array}{l}\text { Ciência } \\
\text { e Saúde } \\
\text { Coletiva }\end{array}$ & $\stackrel{n}{\stackrel{n}{\sigma}}$ & $\begin{array}{l}\text { PET- } \\
\text { Saúde }\end{array}$ & $\begin{array}{l}\text { Universidade } \\
\text { Federal de } \\
\text { Minas Gerais } \\
\text { (UFMG) }\end{array}$ & $\begin{array}{l}\text { Analisar, na perspectiva } \\
\text { dos alunos, o PET- } \\
\text {-Saúde de uma } \\
\text { universidade pública de } \\
\text { Belo Horizonte-MG em } \\
\text { seu primeiro ano e seu } \\
\text { impacto na formação dos } \\
\text { discentes. }\end{array}$ & $\begin{array}{l}\text { Estudo } \\
\text { de coorte } \\
\text { prospectivo } \\
\text { com } \\
\text { abordagem } \\
\text { quantitativa. }\end{array}$ \\
\hline $\begin{array}{l}\text { Freitas, } \\
\text { et al }\end{array}$ & $\begin{array}{l}\text { Repercussões } \\
\text { do PET-Saúde } \\
\text { na formação de } \\
\text { estudantes da área } \\
\text { da saúde. }\end{array}$ & $\begin{array}{l}\text { Escola Anna } \\
\text { Nery }\end{array}$ & $\stackrel{n}{\stackrel{N}{\sigma}}$ & $\begin{array}{l}\text { PET- } \\
\text { Saúde }\end{array}$ & $\begin{array}{l}\text { Duas Instituições } \\
\text { de Ensino } \\
\text { Superior, uma } \\
\text { privada e outra } \\
\text { pública, em } \\
\text { Santa Maria, RS. }\end{array}$ & $\begin{array}{l}\text { Conhecer as } \\
\text { repercussões do PET- } \\
\text { Saúde na formação de } \\
\text { estudantes da área da } \\
\text { saúde. }\end{array}$ & $\begin{array}{l}\text { Estudo } \\
\text { exploratório- } \\
\text { descritivo, } \\
\text { com } \\
\text { abordagem } \\
\text { qualitativa. }\end{array}$ \\
\hline $\begin{array}{l}\text { Fonsêca e } \\
\text { Junqueira }\end{array}$ & $\begin{array}{l}\text { Programa de } \\
\text { Educação pelo } \\
\text { Trabalho para } \\
\text { a Saúde da } \\
\text { Universidade de } \\
\text { São Paulo (Campus } \\
\text { Capital): o olhar dos } \\
\text { tutores. }\end{array}$ & $\begin{array}{l}\text { Ciência } \\
\text { e Saúde } \\
\text { Coletiva }\end{array}$ & $\stackrel{+}{\circ}$ & $\begin{array}{l}\text { PET- } \\
\text { Saúde }\end{array}$ & $\begin{array}{l}\text { Universidade de } \\
\text { São Paulo (USP), } \\
\text { Campus Capital }\end{array}$ & $\begin{array}{l}\text { Obter uma opinião } \\
\text { coletiva, qualificada } \\
\text { e consensual de um } \\
\text { grupo de conhecedores } \\
\text { potenciais (tutores) sobre } \\
\text { o PET-Saúde. }\end{array}$ & $\begin{array}{l}\text { Estudo de } \\
\text { abordagem } \\
\text { qualitativa, } \\
\text { auxiliada } \\
\text { pela técnica } \\
\text { Delphi. }\end{array}$ \\
\hline
\end{tabular}

Fonte: Sistematizado pelos autores. 
A análise dos resultados dos 15 estudos selecionados foi realizada de forma descritiva, sendo dividida em dois subitens, com a finalidade de caracterizar as publicações, sendo eles: perfil das publicações e as categorias encontradas com maior relevância.

Em relação ao perfil dos autores, foi possível constatar que a temática suscitou interesse, sobretudo, de pesquisadores docentes das regiões Sul e Sudeste, seguido da região Nordeste. Tal fato justifica-se pela quantidade de projetos aprovados nessas dadas regiões, pois, a exemplo, somente no primeiro edital do PET-Saúde publicado em 2009, foram selecionados 84 projetos de todo o Brasil, totalizando 306 grupos, que realizaram atividades educativas e de pesquisas em aproximadamente 820 unidades da Estratégia de Saúde da Família no país. Destes, 25 grupos localizavam-se na região Sudeste; 23 na região Sul; 22 na região Nordeste; nove na região Centro-Oeste e cinco na região Norte9 .

A enfermagem destacou-se enquanto categoria profissional predominante dos docentes pesquisadores do objeto em questão, sucedida pelas áreas de medicina e odontologia. Verifica-se, também, autores vinculados à atenção primária, que atuam em parceria com as respectivas instituições de ensino na implementação dos programas de reorientação profissional, além de gestores do setor saúde e graduandos participantes do PET-Saúde na condição de monitores.

A produção científica do objeto de estudo em questão encontra-se disponível, predominantemente, em periódicos da grande área de saúde ( $\mathrm{n}=9$ ), com três publicações em periódicos da área de enfermagem $(n=3)$ e uma publicação em periódico específico da odontologia $(\mathrm{n}=1)$. Embora as publicações dos dois editais do Pró-Saúde datem de 2005 (Pró-Saúde I) e 2007 (Pró-Saúde II), sendo contemplados 354 cursos das diversas áreas de saúde em todo o país, observase que os estudos sobre a temática, identificados nessa busca, foram publicados apenas em 2010 e 2012. Em relação ao PET-Saúde, sabe-se que, no total, foram publicados sete editais: PET-Saúde (2008), PET-Saúde/Saúde da Família (2009), PETSaúde/Vigilância Sanitária (2010), PET-Saúde/Saúde Mental/Crack (2010), Pró-Saúde/PET-Saúde (2011), PET-Saúde/Vigilância Sanitária (2012) e PET-Redes de Atenção (2013). No entanto, na busca realizada, observa-se que somente a partir de 2010 surgem publicações sobre a temática, constando em 2010 e 2012 três publicações por ano, quatro publicações em 2013 e uma publicação em 2014.

A dissertação identificada no Banco de Teses e Dissertações da UFC, no Programa de PósGraduação em Saúde da Família/Campus Sobral, data de 2014 e discorre sobre o Pró-Saúde. Em relação aos 14 artigos identificados, 12 trazem como temática o PET-Saúde e dois versam sobre o Pró-Saúde.

Os estudos em questão tiveram como cenário, em sua maioria (07), instituições de ensino dos estados do Rio Grande do Sul (UFRS, Unochapecó, UFPel, Universidades de Santa Maria) e Minas Gerais (UFMG, Unimontes) com quatro e três publicações respectivamente. Sucedendo esses estão os estados do Paraná (UEL e dois cursos de medicina de Curitiba cujas instituições de ensino não foram identificadas) e Rio Grande do Norte (UERN) com duas publicações cada, e os estados da Bahia (UEFS), Espírito Santo (UFES) e São Paulo (USP) com uma publicação. A única dissertação incluída foi produzida no Ceará tendo como lócus investigativo a Universidade Estadual Vale do Acaraú - UVA.

Em relação aos objetivos, os estudos que versam sobre o Pró-Saúde, buscam, de uma forma geral, compreender a atuação profissional na atenção básica a partir do Pró-Saúde, além de relatar a influência de projetos do Pró-Saúde no processo de formação acadêmica; as publicações inerentes ao tema PET-Saúde objetivam, predominantemente, conhecer as contribuições do programa na formação dos estudantes da área da saúde e seu impacto na integração ensino-serviço-comunidade, além de buscar compreender a percepção dos atores envolvidos. 
Para o desenvolvimento dos estudos, os autores utilizaram, em sua maioria $(n=10)$, métodos qualitativos, seguidos de métodos mistos $(\mathrm{n}=3$ ) e métodos quantitativos ( $\mathrm{n}=2$ ), com utilização predominante de entrevistas e aplicação de questionários como ferramenta de coleta de dados. A análise dos dados ocorreu, sobretudo, mediante categorização temática.

\section{DISCUSSÃo}

A partir da análise das produções coletadas foi possível identificar uma diversidade de achados relacionados às contribuições das experiências da implantação da política de reorientação da formação profissional, tornando-se possível vislumbrar, a partir do exposto, suas potencialidades e avanços, bem como as fragilidades e desafios inerentes aos programas implementados. Para facilitar a compreensão do que será discutido, foram delineadas categorias correspondentes aos resultados emergentes dos estudos selecionados.

\section{O Pró-Saúde e o PET-Saúde na formação dos profissionais de saúde para o SUS}

Em relação ao Pró-Saúde, com o intuito de compreender como os profissionais da saúde se posicionam diante da articulação ensino/serviço a partir do programa, autores ao realizarem estudo na atenção básica de Mossoró-RN verificaram que esses trabalhadores detinham poucos conhecimentos acerca do Pró-Saúde ${ }^{10}$. Os autores apontam que essa falta de conhecimento, associada às dificuldades na integração ensino/serviço, não contribuía para a reflexão e reorientação das práticas de enfermagem, e que se faz necessário repensar saberes e práticas, pactuando mudanças que contribuam com uma formação em saúde que estabeleça um cuidado de qualidade, baseado nos princípios estabelecidos pelo SUS ${ }^{10}$.
Em estudo alhures desenvolvido em Chapecó-RS que objetivou relatar projetos do Pró-Saúde de modo a integrar - por meio de ações pedagógicas o processo de formação acadêmica aos serviços de saúde, concluíram que o Pró-Saúde tem intensificado a integração entre instituição formadora e serviços de saúde, consolidando a atenção básica e seus territórios como cenário prioritário de práticas pedagógicas e assistenciais ${ }^{11}$.

Em relação ao PET-Saúde, pode-se afirmar que as ações desenvolvidas através do programa articulam ensino, pesquisa e extensão e estimulam a reflexão da formação profissional, fomentando um novo olhar para a conformação dos saberes e práticas $\operatorname{cotidianas}^{12}$. As interações propiciadas pelo PETSaúde estimulam a troca de conhecimentos, a interdisciplinaridade e a postura crítica e reflexiva dos mediadores desse processo. Enfatizam que as práticas contribuem para uma formação diferenciada, uma vez que enfatizam os princípios do SUS e as necessidades da população ${ }^{12}$.

O espaço de interação propiciado pelo PET-Saúde vem trazendo aos acadêmicos uma enriquecedora experiência na formação interdisciplinar, voltada para as diretrizes curriculares da educação para os cursos da área da saúde. Essa experiência vem demonstrando a integração de saberes e conhecimentos, no sentido de incentivar a formação de um profissional crítico, reflexivo e integrado na comunidade que busque o trabalho interdisciplinar e em equipe ${ }^{13}$.

$\mathrm{Na}$ perspectiva de alunos participantes, os objetivos propostos pelo programa vêm sendo alcançados, destacando-se o trabalho interdisciplinar e a produção acadêmica voltada para as necessidades do SUS. O programa também contribui para a formação profissional nas áreas de pesquisa, ensino e extensão; os discentes relatam maior interação com equipamentos sociais. O PET-Saúde constitui importante estratégia de formação de recursos 
humanos conforme as necessidades do SUS, por possibilitar o exercício do trabalho em equipe, da comunicação, agilidade e criatividade para lidar com situações adversas, bem como a vivência dos princípios da Atenção Primária integrados à comunidade ${ }^{14}$.

\section{Desafios e limitações do Pró-Saúde e PET-Saúde na reorientação do ensino}

Em relação aos desafios inerentes ao Pró-Saúde, há a necessidade de maior engajamento de seus atores na consolidação dos processos em prol da formação superior e da Educação Permanente em Saúde ${ }^{11}$. Seguindo essa perspectiva, analisando-se a atuação do Enfermeiro para a Atenção Básica no curso de Enfermagem de uma instituição de ensino do interior do Ceará segundo os eixos norteadores do Pró-Saúde, observou a necessidade de fortalecimento da integração ensino-serviço vivenciado na formação do enfermeiro na referida instituição. Aponta-se a necessidade de discussão crítica e reflexiva sobre as práticas, por todos os participantes no processo formativo, visando à transformação da própria prática e da gestão das organizações envolvidas, de modo a fortalecer uma formação de enfermeiro para o SUS ${ }^{15}$.

Sobre o PET-Saúde, corroborando essa compreensão, um estudo desenvolvido em uma universidade do Rio Grande do Sul reforça a impressão de que o PETSaúde ainda não provocou todas as modificações esperadas nos cenários de prática ${ }^{16}$. Experiências de implantação do programa em uma instituição de ensino de Minas Gerais confirmam essa ideia, sinalizando a necessidade de maior integração entre os cursos de graduação de modo a permitir compatibilidade e flexibilidade curricular, com maior integração teórico-prática. Além disso, o treinamento para a docência entre os profissionais que recebem alunos também é um dos desafios que emergem do PET-Saúde ${ }^{16}$.
Em estudo desenvolvido com o intuito de investigar a percepção dos alunos quanto à influência do PETSaúde na formação profissional, identificou-se que o programa determinou avanços, mas também apresentou limitações em relação às mudanças nos processos de formação de recursos humanos na área da saúde, como a heterogeneidade de participação dos alunos nas atividades propostas; potencial restrito para impulsionar atividades que não são realizadas tradicionalmente na Unidade de Saúde; a indisponibilidade de horário dentro da grade curricular dos alunos; restrição da interdisciplinaridade ao grupo tutorial, visto a resistência de profissionais não participantes do PET-Saúde em relação ao programa ${ }^{18}$.

$\mathrm{Na}$ percepção de tutores, os principais limites do programa referem-se à falta de comprometimento manifestada por alguns estudantes, a incompatibilidade entre os horários dos participantes e o despreparo pedagógico dos preceptores enquanto mediadores do processo de aprendizagem ${ }^{19}$.

\section{CONSIDERAÇÕES FINAIS}

A elaboração de uma revisão integrativa sobre a reorientação profissional em saúde permitiu concluir que o Pró-Saúde e o PET-Saúde, enquanto ferramentas de transformação do ensino e do trabalho em saúde, vêm promovendo impactos significativos na formação profissional e, consequentemente, na qualificação dos trabalhadores para atender as demandas do sistema público de saúde, o que reflete o crescimento e consolidação desses programas em relação aos objetivos estabelecidos pela referida política. Contudo, é possível verificar na prática a existência de algumas limitações e fragilidades no processo de implementação dos programas, o que se constitui como desafios a serem enfrentados para o alcance efetivo de mudanças no ensino na área da saúde.

Além disso, para suprir a lacuna identificada nessa busca na realidade local e regional, aponta-se a 
necessidade do desenvolvimento de estudos que busquem identificar evidências de efetividade do Pró-Saúde e PET-Saúde nas universidades públicas do interior do Ceará, com o intuito de averiguar o impacto desses programas na formação profissional e suas repercussões no sistema de saúde local, como também identificar novos achados que subsidiem estratégias de aprimoramento para a sua operacionalização.

Ao proceder com a construção desse estudo, é relevante enfatizar a dificuldade dos autores em identificar um quantitativo significativo de artigos sobre a temática a partir da busca implementada, sendo realizadas inúmeras tentativas de cruzamentos com diferentes palavras-chaves. Considerando o número de editais publicados do Pró-Saúde e PET-Saúde e a quantidade de Universidades contempladas, acredita-se que haja uma produção científica mais vasta abordando experiências concretas da implementação desses programas nas instituições de ensino envolvidas.

\section{REFERÊNCIAS}

1. Feuerwerker LCM. Educação na saúde: educação dos profissionais de saúde - um campo de saber e de práticas sociais em construção. Rev Bras Educ Med. 2007; 31(1):3-4.

2. Batista CB. Movimentos de reorientação da formação em saúde e as iniciativas ministeriais para as universidades. Barbaroi. 2013; 38:97-125.

3. González AD, Almeida MJ. Integralidade da saúde norteando mudanças na graduação dos novos profissionais. Ciência \& Saúde Colet. 2010; 15(3):757-762.

4. Dias HS, Lima LD, Teixeira M. A trajetória da política nacional de reorientação da formação profissional em saúde no SUS. Ciência \& Saúde Colet, Rio de Janeiro, v.18, n.6, p.16131624, jan./jun, 2013.

5. Brasil. Ministério da Saúde. Programa Nacional de Reorientação da Formação Profissional em Saúde - PRÓSaúde: objetivos, implementação e desenvolvimento potencial.
Brasília: Ministério da Saúde, 2007.

6. Brasil. Ministério da Saúde. Pró-Saúde: programa nacional de reorientação da formação profissional em saúde. Brasília: Ministério da Saúde, 2005. 77 p.

7. Brasil. Portaria no 1 , de 5 de fevereiro de 2010. Brasília: Diário Oficial da União, 2010.

8. Galvão CM, Sawada NO, Trevizan MA. Revisão sistemática: recurso que proporciona incorporação das evidências na prática da enfermagem. Rev Latino-am Enferm. 2004; 12(3):549-56.

9. Brasil. Ministério da Saúde. Secretaria de Gestão do Trabalho e da Educação na Saúde: SGETS: políticas e ações. Brasília: Ministério da Saúde, 2011. 32p.

10. Morais FRR et al. A reorientação do ensino e da prática de enfermagem: implantação do Pró-Saúde em Mossoró, Brasil. Rev Gaúcha Enferm. 2010; 31(3): 442-9.

11. Kleba ME et al. Práticas de reorientação na formação em saúde: relato de experiência da Universidade Comunitária da Região de Chapecó. Ciência, Cuidado e Saúde. 2012; 11(2):408414 .

12. Morais FRR et al. A importância do PET-Saúde para a formação acadêmica do enfermeiro. Trabalho, Educação e Saúde. 2012; 10(3):541-551.

13. Pereira CS et al. Contribuições da educação tutorial e reorientação da formação para enfermagem: uma salada saudável! Rev de Enferm UFSM. 2013; 3(1):367-373.

14. Pinto ACM et al. Percepção dos alunos de uma universidade pública sobre o Programa de Educação pelo Trabalho para a Saúde. Ciên \& Saúde Colet. 2013; 18(8):2201-2210.

15. Brito MCC. Formação do enfermeiro para a atenção básica: análise da orientação teórica, cenários de prática e orientação pedagógica a partir de um curso de graduação [Dissertação]. Sobral (CE): Universidade Federal do Ceará; 2014.

16. Neumann CR, Miranda CZ de. Ensino de Atenção Primária à Saúde na Graduação: Fatores que Influenciam a Satisfação do Aluno. Rev Brasil de Educ Méd. 2012; 36(1):42-49.

17. Leite MTS et al. O Programa de Educação pelo Trabalho para a Saúde na Formação Profissional. Rev Bras de Educ Méd. 2012; 36(1):111 - 118 .

18. Caldas JB et al. A Percepção de Alunos Quanto ao Programa de Educação Pelo Trabalho para a Saúde - PET-Saúde. Rev Bras Educ Med. 2013; 36(1):33-41.

19. Fonseca GS, Junqueira SR. Programa de Educação pelo Trabalho para a Saúde da Universidade de São Paulo (Campus Capital): o olhar dos tutores. Ciênc Saúde Colet. 2014; 19(4):1151-1162. 